\section{Digital Literacy: Survival Skill for Librarians in the Digital Era}

\section{Isa Sidi Attahir}

University of Abuja, Nigeria
Information Impact: Journal

of information and

knowledge management

2018, Vol. 9 (4) Pg 107-116

ISSN: $2141-4297$ (print)

ISSN: 2360 - 994X (e-version)

\title{
Abstract
}

The paper is aimed at investigating what digital literacy is, and determining through existing literature if researchers particularly in Nigeria possess this skill, as well as to investigate what initiatives have been done in Nigeria regarding digital literacy skill. This is a review paper, as such extensive review of existing literature on the topic and the researcher's work and personal experiences were brought to bear to help discuss the objective of the study. The main objective of this study is to determine the level of digital literacy among librarians and efforts in Nigeria in order to design a training programme for researchers. Additionally, a training programme was designed on DL to train researchers in Nigeria. Conclusions based on the literature reviewed revealed that there is still low digital literacy among librarians and as a result it was recommended that more efforts should be made to incorporate digital literacy programmes in the institutions' curricular, as well as more training programmes for librarians.

\section{Keywords: Digital literacy, librarians, libraries, Nigeria.}

\section{Introduction}

Information and Communication Technologies' (ICTs) developments such as digital technologies (social media and multimedia communication) have greatly revolutionized how things are done. They have greatly impacted on every sphere of human endeavor: social, industry, education, agriculture, health etc. Libraries have thus not been left out in this change. These ICTs have become an essential component of the daily activities of their users: faculty, researchers and students, either for interpersonal or organizational communication purposes (Eshet-Alkalai \& Soffer, 2012). Now, the difficulty is no longer the unavailability of information but rather how to navigate through the maze of information available online. It has thus become very important that people are able to effectively access these vast quantities of information online (Eshet-Alkalai \& Soffer, 2012). As such, libraries are now frantically looking for newer ways to ensure that their users are able to fully utilize the resources at their disposal. Libraries are now being challenged to assist their users find the information they need in varied formats, at the right time and remotely too. Libraries have therefore found it necessary to educate their users especially researchers to take advantage of ICTs to enhance access to the information resources as well as improve upon their research practices. As Kirkland (2014), puts it "there has never been such a 
great opportunity to leverage the collaborative learning model of the library as a learning commons and the professional leadership of teacher-librarian to address issues around digital literacy".

Though technology has made information much more available to people, the large scale of its quantity has also posed access challenges. Though many people use this technology and are quite conversant with its use, they do not really know how to effectively use it in learning contexts which require in-depth skills, critical thinking, digital literacy and communication skills. As such, it has become essential for users to master a broad range of technological skills, which are collectively called "Digital Literacy" (DL). Thus, users will have to become digitally literate in order to effectively navigate the current information terrain where they do not only consume but also create knowledge in nonlinear environments. Users now have to be able to learn, collaborate and effectively solve problems in a virtual learning environment and also communicate on virtual social platforms. Thus this literacy is not only about being knowledgeable in the use of computers and the internet but also includes various epistemological and ethical issues.

\section{Statement of the problem}

Academic libraries are libraries that are found in higher institutions of learning with the main objective of supporting the teaching, learning and research activities that take place in their parent institutions. With the proliferation of Information and Communication Technologies, the library has also embraced the new trend and embedded it into all its activities due its numerous advantages which range from: ease of access to information, multiple access points, multiple resources, remote access, 24-hour availability of materials, ease of collaboration, etc. This development though highly advantageous, came with its own price in the form of the need for the skills to manipulate and navigate the ICT facilities that are used in the provision of information and services by the libraries for the researchers to be able to get exactly what information and resources they are looking for from the library. The problem is: What DL initiatives exist in Nigeria and how can they be employed by libraries to benefit researchers in Nigeria? To investigate this problem, the following questions were asked:

- What digital literacy initiatives exist in Nigeria?

- How can DL skills be imparted to researchers in Nigeria?

- What other programmes can be implemented to enhance researchers' acquisition of digital literacy skills in Nigeria?

\section{Methodology}

This is a review paper as such thorough review of related literature was employed as well as the researcher's personal and work experiences to address the research questions. The researcher retrieved information from both online academic databases and other online resources. Databases consulted included: Directory of Open Access Journals (DOAJ), CORE, Ebscohost, Emerald, Directory of Open Access Journal Search Engine (OAJSE), JSTOR, Google Scholar, and Google. 


\section{Review of Related Literature \\ Digital literacy (DL)}

The term digital literacy (DL) is increasingly being used to describe new competencies that equips individuals with the confidence and ability to effectively use digital devices and the internet to find, assess, generate new information and communicate it to others (Zwimpfer, n.d.). He further explains that in order to achieve this, one has to have some understanding of digital technologies and possess some technical skills to use them. DL is usually seen as the second phase of digital competency and that the first phase is digital awareness which is knowing basics digital activities such as knowing what the computer is used for and sending emails. While the second phase is digital literacy which involves skills for daily life, digital competency which is office/workplace skills, and digital expertise which is advanced job roles skills (Zwimpfer, n.d.).

Khan and Waheed (2015) have defined DL as the ability to effectively perform tasks in the present digital information environment. They further indicate that when a person is able to interpret digital media like sound, images, text as well as generate new information from it, then that person is said to be digitally literate. DL thus, is a combination of literacies. These include photo visual literacy (being able to rearrange digital content to create new meaning); branching/hypermedia literacy (ability to use non-linear information seeking strategies to create knowledge from independent pieces of information accessed in a non-orderly manner); information literacy (the practice of always questioning information) and socio-emotional literacy ( $\mathrm{Ng}, 2012)$

DL, from the foregoing, refers to the mastering and use of a wide range of technological, cognitive and social competencies. These competencies include but not limited to the ability to effectively operate computers and navigate the net, manage huge volumes of information, evaluate its reliability and critically assess these technological tools Lankshear \& Knobel, (2006). Again, DL includes the ability to effectively collaborate in virtual learning environments to solve problems as well as communicate well in technologically mediated social participatory environments. Thus DL is not limited to simply knowing the computer and internet operations and orientations but also involves a variety of knowledge theories and ethical issues due to the special nature of digital technologies.

However, for DL to effectively serve its purpose of empowering the 21 st century librarian to be able to utilize the opportunities technology presents them there must be effective internet connectivity referred to as digital inclusion which is the backbone of DL development (Martzoukou\& Elliot, 2016). The main concepts that underlie DL include, ICT literacy, computer literacy, Internet literacy, and media literacy. Brown (2014) and Zwimpfer, (n.d) stated that digitally literate people have the capabilities to:

- Access digital technologies, like computers other mobile devices and the internet;

- Search the internet for information as well as verify the information sources;

- Competently and efficiently use digital technologies for work;

- Protect personal data while avoiding malicious websites;

- Utilize technological communication channels such as emails, and social media to keep in touch with others;

- Understand and use online marketing platforms, online banking and other transactions; 
- Purchase and install software on digital devices and are able to use online tutorials and help to teach themselves simple tasks;

- Complete online forms, share photos and videos online; and

- Understand copyright law.

\section{Advantages of digital literacy}

Digital literacy is an invaluable skill that needs to be acquired by all librarians because of its numerous advantages which include:

Improved quality and quantity of research: This is because the researcher will be able to navigate all the databases to get the information materials that are necessary for his/her research thereby being exposed to a wide range of data hence improving on the quality and quantity of research.

Time saving: Being digitally literate saves the time of the researcher in that the time someone would have spent looking up for information materials is reduced since the person has the skills for using the internet and searching for databases.

Improved Quality of teaching: Since the teachers will have the skills of searching for information, their quality of teaching will improve. They will be able to get a variety of information and most of latest information which is useful to their students.

Increased usage of e-resources: When users are digitally literate, even though they use textbooks or printed materials, they would always want to use the internet and e-resources and hence increasing the usage of e-resources.

Justified relevance of librarians: Since it is the librarians who train researchers in finding information resources online for example searching for relevant databases, the use of search terms and search engines. This puts the librarians on top because those people they assist can never forget them hence justifying their relevancy through digital literacy.

Increase the visibility of the researcher university: Through digital literacy, the university can be more visible because more and more researchers will be pouring in day in day out because they are sure that they will complete their research on time since they will be able to locate relevant information materials easily.

Performance of students will improve: Being digitally literate, students will be able to find useful information to help them in their studies. They not only depend on the lecturer's notes thereby helping them discover more information hence improving their performance.

Better decision making: When you have limited ways to get information your choices are also limited. Digital literacy helps someone to search, study, analyze and compare the vast resources available. 


\section{Uses and Implementation of DL}

Digital literacy is increasingly being referred to as "survival skill" for librarians if they want to derive maximum benefit from the opportunities the digital evolution offers them. DL as discussed earlier consists of a number of literacies which are all needed by librarians and which could be acquired. Eshet-Alkalai (2004) explains in his study of the usefulness of digital literacies to users that photo-visual literacy is the art of reading visual representations. This art dates back to historical times when symbols were used to communicate but was eventually developed into alphabets. This form of communication did not require high level of cognitive mediation as compared to the modern day alphabets. In contrast, the use of photo-visual communication in digital environments shows the opposite, where computer interfaces used text and gradually developed into graphic interfaces that is using the principle of "using vision to think" this create a very effective photo-visual communication which is able to communicate in the users language. This method has been found in usability studies that it is easier for most users to learn using graphic interfaces because the natural visual communication is applied (Eshet-Alkalai, 2004). It has been discovered that this kind of interface allows users to use a unique form of digital literacy such as photo-visual literacy which enables them read intuitively and freely and helps a better understanding of instructions and messages represented in visual form. Studies have further revealed that doing photo-visual work in graphic environment greatly reduces time needed to work in a digital environment thereby making it necessary to utilize this literacy when designing a user interface design.

Reproduction literacy is the art of innovatively reusing existing material which began with the invention of the printing press by Gutenberg in 1455. This marked a great revolution in the production and sharing of information. Then the emergence of computer digital production further improved reproduction processes. This opened new opportunities for scholars and artists to be able to reproduce their creations. There however arises a challenge when reproduction is done in academia with issues of copyright and plagiarism. There is a difficulty of determining how much change is needed for research output to be considered original, real or legitimate. Notwithstanding this challenge however, improved capabilities of computers and digital editing programmes have made it easier for artists and academics to reproduce their original works. The skill for writing original academic output using digital technologies for reproducing the text is referred to as reproductive literacy and has greatly improved scholarly works. Eshet-Alkalai, (2004).

Another digital literacy skill of great importance and which has greatly enhanced scholarship is branching/hypermedia literacy. This involves a great deal of hypermedia and nonlinear thinking. Hypermedia technologies give scholars new opportunities of using nonlinear ways to access information, rather than the traditional relatively linear data searching techniques. This technology allows researchers to freely navigate through various knowledge domains but this involves the use of large quantities of separate pieces of information retrieved using nonlinear methods. It also allows researchers the chance to multitask. Researchers are also able to perform nonlinear searching as well as use associative branching through various fields of knowledge. This helps develop the multi thinking abilities of researchers, this process is what is termed branching or hypermedia literacy. Librarians need this literacy in order to be 
able to construct knowledge from independent pieces of information which is used to solve difficult and demanding activities. This literacy is a necessity for librarians as well as researchers who aim at working in knowledge construction jobs especially in this digital environment, it is a must have literacy and should be seen as a "survival skill" for librarians. Eshet-Alkalai (2004).

Socio-emotional literacy deals with the sociological and emotional aspects of working in the cyberspace. The growth of the Internet and other digital platforms and communication channels have offered great opportunities for online collaborative and information sharing in varied ways. Examples of such platforms include discussion groups, learning communities and chat rooms. These new opportunities however also come with a few challenges such as verifying people's identities on these platforms, genuineness of information given on such platforms to mention but a few. These challenges make it imperative that librarians exercise great deal of care when using these platforms in order to derive maximum benefit from participating in them. This skill seems the most complex of all the skills since it requires that the librarian displays a high level of maturity, analytical and critical qualities and branching literacy in order to understand and effectively use the socio-emotional literacy skill (Eshet-Alkalai, 2004).

The impact of digital literacy on the lives of librarians cannot be over emphasized in this rapidly changing technological environment. The acquisition of this skill by librarians has enabled them to effectively use finding aids to navigate the huge maze of information available to them to find both print and digital information resources relevant to them. This skill has also enabled them to adopt practical ways to overcome access difficulties. Librarians are now able to use informal electronic ways to share information with their colleagues (Hart \&Kleinveldt, 2011)

\section{Role of librarians in the Provision of Digital Literacy Skills}

All librarians need to be equipped with new skills of technologies such as resource sharing, social networking, surfing the net, instant messaging, blogging and host of other digital oriented activities (Emiri, 2015). Cordell (2013) argued that all librarians need to be equipped with skills related to how to navigate the library website, how to get to a search page or find the advanced search page, how to find the help files, how to save or export citations and full texts, how to set up an account in a social media site, how to upload files to that site, how to comment on others' postings. Being equipped with all these will help them on their job to assist their users to access desired information at the right time (Abertawe, 2013). These related skills need to be capacitated to researchers so as to enable them to produce desired output of their research.

Librarians and library users need to be aware of digital literacy in this current era of science and technology. Library users of this digital era are more interested in utilizing digital tools during their quest for information (Khan $\&$ Waheed, 2015). As a result, it is essential for libraries to provide digital literacy trainings to their users and educate them on the effective use of digital information sources offered by libraries. 
Rapid technological changes are altering the traditional ways of performing different activities in libraries. Digital technologies such as e-book readers, social media, mobile technologies and multi-player online games are actually altering the traditional modes of learning, knowledge construction, cognitive and social skills, information distribution and consumption, as well as social participation and relationships (Eshet-Alkalai, \&Soffer, 2012). Therefore, these changes need to be copied by all libraries and librarians in order to fit in the digital environment.

Skills in information retrieval, evaluation and management are essential for the researchers and librarians. These skills will create wider platform especially for researchers who want their research to reach an international audience. In this environment of innovative developments, libraries expand their role not only to the adoption of electronic materials, but also to the development of new methods for the organization of new materials enhancing their services for the final receiver of information (Nikitakis, Papadourakis\&Sitas, 2010). Abertawe (2013) furthered that to develop key lifelong learning skills, a person with digital literacy skill will be confident in navigating an information-overloaded world. They will be able to use those skills to their advantage in any learning situation. Therefore, libraries need to keep on capacitating the related technology of digital literacy to their users.

\section{Digital Literacy Implementation and Initiatives in Nigeria}

There are many studies conducted to assess the situation of the digital literacy of librarians in Nigeria. For instance, Issa, Amusan and Dauda (2009) concluded that digital literacy skills have not taken the desired firm root among their subjects of study. Emiri, (2015) concurred with this finding when he asserted that librarians', who form part of researchers in higher institutions, level of digital literacy is low. Tonubarikpai, Kinanee and Ekeleme (2012) also conducted a research in the same vein; their major finding of the study was that the level of digital literacy amongst their respondents was generally low.

The above studies show that the digital literacy of librarians in Nigeria is still low. This situation is prevalent in Nigeria among librarians, because the promotion of academics in Nigeria is based on the numbers of their publications and not their digital literacy skills. Other reasons are the phobia for ICT, inadequate ICT infrastructure including inadequate and slow bandwidth, and lack of awareness among librarians.

In light of the above, libraries in Nigeria are putting in place various measures to see that they improve the digital literacy of librarians. In this regards, many academic libraries have access to databases, digitized their catalogues, and built institutional repositories. They also organize training sessions for researchers and lecturers in their institutions on how to use these facilities. Also the Nigerian Library Association has an IT Section which organizes seminars and workshops for librarians on ICT. Also, the Librarians' Registration Council

\section{Conclusion and Recommendations}

The discussion revealed that librarians in Nigeria possess low digital literacy. Also, libraries in Nigeria are embracing the new trends in ICT and are providing trainings and workshops to update librarians on digital literacy. Problems encountered in training librarians 
on digital literacy include inadequate ICT infrastructure, power outages, slow bandwidth and fear of ICT. Based on the findings of the study, a training programme is proposed for libraries in Nigeria as follows:

This programme should be held annually for the duration of a week at the beginning of each session so as to train librarians and researchers on digital literacy. The programme is to be held in two sessions per day, morning and afternoon sessions. The morning sessions will be lectures while the afternoon sessions will be for hands-on practical. The contents of the programme are as follows:

\begin{tabular}{|l|l|l|l|l|l|}
\hline Days & \multicolumn{1}{|c|}{$\mathbf{1}^{\text {st }}$ Session } & $\mathbf{2}^{\text {nd }}$ Session & BREAK & $\mathbf{3}^{\text {rd }}$ Session & $\mathbf{4}^{\text {th }}$ Session \\
\hline Monday & $\begin{array}{l}\text { Opening ceremony and } \\
\text { general introduction }\end{array}$ & $\begin{array}{l}\text { What is a digitally } \\
\text { literate learner? }\end{array}$ & B & $\begin{array}{l}\text { From digital literacy to } \\
\text { digital scholarship }\end{array}$ & $\begin{array}{l}\text { Key issues in } \\
\text { developing a DL trail: } \\
\text { what are we really } \\
\text { revealing online? }\end{array}$ \\
\hline Tuesday & $\begin{array}{l}\text { Personal information } \\
\text { management (PIM) }\end{array}$ & $\begin{array}{l}\text { Persona Information } \\
\text { Management }\end{array}$ & R & Practical & practical \\
\hline Wednesday & $\begin{array}{l}\text { Cloud services and } \\
\text { storage }\end{array}$ & $\begin{array}{l}\text { Cloud services and } \\
\text { storage }\end{array}$ & E & Practical & practical \\
\hline Thursday & Social media training & Social media & A & Practical & practical \\
\hline Friday & Publishing tools & Publishing tools & K & Practical & practical \\
\hline
\end{tabular}

This research is also recommending that libraries should be involved in the following ways:

- More effort is made in the study countries to incorporate DL and RL programmes in their institutional curricular

- More workshops, seminars and other training programmes on DL and RL be organized regularly

- There should be more collaboration between Librarians and researchers and faculty to ensure effective implementation of these programmes 
- Librarians themselves need to be well equipped to be able to run these programmes, hence, libraries should commit some funds into the training of their staff

- Encourage researchers to embrace ICTs as well as take the acquisition of DL and RL skills as very essential to their very existence Rephrase

Check out all the references

\section{Referencess}

Abertawe, P. (2013). Information and digital literacy strategy. Swansea: Swansea University.

Brown, S. A. (2014). Conceptualizing digital literacies and digital ethics for sustainability education. International Journal of Sustainability in Higher Education, 15 (3), 280-290.

Cordell, R. M. (2013). Information literacy and digital literacy: Competing or complementary? Illinois: Northern Illinois University.

Emiri, O. T. (2015). Digital literacy skills among librarians in university libraries in the 21st century in Edo and Delta states, Nigeria. International journal of scientific \& technology research, 4 (8), 153-159.

Eshet-Alkalai, Y. \& Soffer, O. (2012). Navigating in the digital era: Digital literacy: Socio-cultural and educational aspects. Educational Technology and Society, 15(2), 1-5.

Eshet-Alkalai, Y. (2004). Digital literacy: a conceptual framework for survival skills in the digital era. International Journal of Educational Multimedia and Hypermedia, 13 (1), 93-106.

Hart, G, \& Kleinveldt, L. (2011). The role of an academic library in researchers' perspectives at a South African University of Technology. Communications in Information Literacy, 7(2), 177-183.

Issa, A. O., Amusan, B. \& Dauda, D. U. (2009). Effects of information literacy skills on the use of e-library resources among students of the University of Ilorin, Kwara State, Nigeria. Library philosophy and practice (e-journal), Retrieved from http://digitalcommons.unl.edu/libphilprac/245 on 24th November, 2017.

Khan, S. A. \& Waheed, A. (2015). Digital literacy practices for library users at Government College University Libraries. Lahore: University Libraries.

Kirkland, A. B. (2014). Digital literacy: Opportunities in the learning commons school libraries in Canada. Canada: CLA voices for school libraries.

Lankshear, C. \& Knobel, M. (2006). Digital literacies - concepts, policies and practices. Retrieved from http://scholar.google.co.za/scholar_url?url=http://eprints.jcu.edu.au/27788/1/27788_Lankshear_and_Knobel_2008.pdf\&hl=en \&sa=X\&scisig=AAGBfm2P4CQED_XXIVkxwe1R1L0X3b_3yg\&nossl=1\&oi=scholarr\&sqi=2\&ved=0ahUKEwiJzLiw38PQ AhWBOsAKHUfVCP0QgAMIHigAMAA [Accessed 20th November, 2016 
Martzoukou\& Elliot, (2016). Helping the next 4 billion go online part I: Design research for digital literacy education.

International Journal for Service Learning in Engineering, Humanitarian, Engineering and Social Entrepreneurship, 11(2), 70-78

Ng, W. (2012). Can we teach digital natives digital literacy? Computers \& Education. 59(2), 1065-1078.

Nikitakis, M., Papadourakis, G. \& Sitas, A. (2010). From library skills to information literacy. Heraklion: Crete.

Tonubarikpai, J., Kinanee, J. \& Ekeleme, C. (2012). A study of computer literacy among trainee teachers in a Nigerian university of education. Global Voice of Educators, 1 (1), 29-45.

Zwimpfer MNZM, L. (n.d.). Digital literacy- what are we really talking about? Retrieved from www.slanza.org.nz/uploads/9/7/5/5/9755821/collected_18.pdf on 20th November, 2016. 